\title{
Oncologic Results of Supracricoid Laryngectomy: Results From Two Tertitory Centers
}

\section{Larenks Kanseri tedavisinde SKL Cerrahisi ve Onkolojik Sonuçları: 3.Basamak İki Merkezden Sonuçlar}

\author{
Necati Enver ${ }^{1}$, Akın Şahin ${ }^{1}$, Ali Yumusakhuylu ${ }^{1}$, Asli Sahin-Yilmaz², Cagatay OYSU ${ }^{2}$ \\ ${ }^{1}$ Marmara Üniversitesi Pendik Eğitim ve Araştırma Hastanesi, Kulak Burun ve Boğaz Hastalıkları Anabilim \\ Dal, İstanbul \\ ${ }^{2}$ Ümraniye Eğitim Araştırma Hastanesi, Kulak Burun ve Boğaz Hastalıkları Anabilim Dalı, İstanbul
}

Dergiye Ulaşma Tarihi: 18.09.2020 Dergiye Kabul Tarihi: 22.11.2020 Doi: 10.5505/aot.2020.56873

\begin{abstract}
ÖZET
GiRiş ve AMAÇ: Larenks kanseri tüm baş boyun kanserleri arasında en sık görülen ikinci kanserdir ve önemli bir morbidite ve mortalite nedenidir. Suprakrikoid larenjektomi cerrahisi, larenks fonksiyonlarının mümkün olduğunca korunmasına imkân veren etkili bir tedavi yöntemidir. Çalışmamızda kliniğimizde son 10 yıl içinde yapılan açık parsiyel larenks cerrahi vakalarının histopatolojik parametrelerini ve onkolojik sonuçlarını paylaşacağız.

YÖNTEM ve GEREÇLER: Ocak 2009 ve Temmuz 2019 arasında kliniğimizde histopatolojik olarak larenks yassı hücreli karsinom tanısı almış ve suprakrikoid larenjektomi cerrahisi uygulanmış 47 hastanın verileri retrospektif olarak incelendi. Hastaların sosyodemografik özellikleri, tümör spesmenlerinin histopatolojik özellikleri ve sağkalım analizleri değerlendirmeye alındı.

BULGULAR: Hastaların 29'unda (\%61.7) erken evre larenks kanseri saptanmış olup, 18'inde (\%38.3) ileri evre larenks kanseri mevcuttur. Larenks kanser 29 olguda (\%61.7) glottik yerleşimli olup lenf nodu tutulumu glottik yerleşimli olgularda anlamlı derecede daha az olarak saptanmıştır $(p<0.001)$. 5-yıllık genel sağkalım \%74.5 olarak saptanmışken, erken ve ileri evre olgularda 5 -yıllık genel sağkalım $\% 88.5$ ve $\% 69.2$ olarak saptanmıştır.

TARTIŞMA ve SONUÇ: Larenks kanseri tedavisinde tedavi başarısının değerlendirilmesinde en önemli iki ölçüt sağ kalım süresi ve organ fonksiyonun devamlıı̆̆ıdır. Larenks kanserlerinin tedavisinde suprakrikoid larenjektomi önemli araçlardan biridir. Cerrahi teknik ve onkolojik kurallara bağlı kalındığında uygun hastalarda fonksiyonel bir larenksi koruyarak hastalarda kalıcı iyileşme sağlamak mümkündür.

Anahtar Kelimeler: Larenks Neoplasmlari, Larenks Neoplazmlari/Cerrahi, Sağ kalım analizi
\end{abstract}

\section{ABSTRACT}

INTRODUCTION: Larynx cancer is the second most frequent head and neck cancer and important cause of morbiditity and mortality. Supracricoid laryngectomy is one of the open partial laryngeal surgerical techniques which is an important tool for treatment of laryngeal cancer. The purpose of this study was to evaluate the oncological outcomes of laryngeal carcinoma patients treated with supracricoid laryngectomy.

METHODS: A total of 47 cases were retrospectively analyzed from two tertiarian head and neck clinics with laryngeal carcinoma that underwent supracricoid laryngectomy from 2009 to 2019. Sociodemographic characteristics, histopathologic characteristics of tumor specimens, and survival analysis were assessed.

RESULTS: Early stage laryngeal cancer was detected in $29(61.7 \%)$ of the patients, and $20(38.3 \%)$ of the patients had advanced laryngeal cancer. In 29 cases (61.7\%) larynx cancer was located in glottis and lymph node involvement was found to be significantly less in cases with glottic location $(p<0.001)$. While 5 -year overall survival was $74.5 \%, 5$-year overall survival was $88.5 \%$ and $69.2 \%$ in early and advanced stage cases.

DISCUSSION AND CONCLUSION: The two most important factors in the determination of successful treatment in treating laryngeal cancer are survival time and preserving laryngeal function. Supracricoid laryngectomy is one of the key tools used in treating laryngeal cancers. Through preserving a healthy larynx in appropriate patients, it is possible to provide permanent improvement while adhering to the surgical technique and oncological rules.

Keywords: Laryngeal Neoplasms, Laryngeal Neoplasms/surgery, Survival Analysis

\section{Giriș:}

Larenks kanseri tüm baş boyun kanserleri arasinda oral kalite kanserlerinden sonra en s1k görülen ikinci kanserdir. Dünyada her sene 200.000 yeni larenks kanseri vakas1 görülmekte ve insidans1 2,7/100.00'dir
(1).Erkeklerde 4,8 kat daha sik görülen bu hastalıkta en önemli risk faktörü tütün ve tütün ürünleri kullanımıdır. Son yıllarda özellikle sigara tüketiminin azalmasiyla birlikte insidans1 belirgin olarak azalmakla birlikte 
mortalitesinin hala \%63 olmasiyla dikkat çekmektedir. ${ }^{1}$

Larenks kanseri yüksek oranda tedavi edilebilen bir kanser türüdür (2).Ama hastalığın yerleştiği bölge nedeniyle tedavide temel amaç sağ kalımı sağlamak kadar larenksin yapisal ve fonksiyonel olarak da korunmasidir. Larenksin solunum, yutma ve konuşma işlevlerinin devam ettirilmesi hayat kalitesinin en önemli bileşenlerindendir, bu nedenle ileri evre kanser hastalarında bile organ koruyucu tedaviler öncelenmelidir.

Son yirmi yılda, larenks kanseri tedavisi yaklaşımı önemli ölçüde değişmiştir. Daha önceleri ilk tedavi modalitesi olarak hemen her hastada açık parsiyel larenks cerrahisi veya total larenjektomi uygulanırken, şu anda bu cerrahiler diğer tedavi modalitelerinden sonra hastalığın tekrarladığı durumlarda kurtarıcı(salvaj) tedavi olarak kullanılmaktadır (7).Bu değişim trendinin en önemli nedeni son y1llarda transoral endoskopik lazer cerrahisi (TLC), Radyoterapi (RT), Kemoterapideki (KT) gelişmelerdir. Sıklıkla bu tedavilerle elde edilen sonuçlar düşük morbiditeye ve yüksek fonksiyonel korumaya sahiptir. Ama bu tedavilerin başarısız olduğu hastalarda ve seçilmiş vakalarda SKL gibi açık parsiyel cerrahiler hala kullanılmaktadır.

Suprakrikoid larenjektomi (SKL) ilk olarak 1959' da Majer ve Rieder tarafindan tanımlanmış ve 1974 'te Piquet ve arkadaşları tarafindan geliştirilmiştir $(3,4)$. Larenks karsinomu tanılı uygun vakalarda bu teknik artık çok sayıda cerrah tarafından kabul görmekte ve uygulanmaktadır. SKL, vokal kordlar, ventriküller, epiglotlar ve paraglottik ve preepiglotik boşluklar olmak üzere tüm tiroid kıkırdağının çıkarılmasını içermektedir. $\mathrm{Bu}$ cerrahi prosedürde krikoid kıkırdak, hyoid kemik ve en az bir fonksiyonel ve hareketli aritenoidkıkırdak korunmaktadır. SKLeksizyon sonrasında yapılan rekonstrüksiyon türüne göre sinıflandırılmaktadır;

krikohiyoidoepiglottopeksi ve krikohiyoidopeksi $(5,6)$.

SKL cerrahisi organ koruyucu bir tedavi seçeneği olarak hala klinik pratikte önemimi korumaktadır. Onkolojik sonuçların paylaşımı bu cerrahi tekniğin değişen tedavi trendleri arasındaki yerini anlatmakta önem taşımaktadır. Bu çalışmada 3.basamaktedavi merkezi olan iki kulak burun boğaz kliniğinde yapılmış suprakrikoid larenkscerrahilerive bu hastaların onkolojik takiplerinin sonuçları paylaşılmıştır.

\section{Gereç ve Yöntem:}

Ocak 2009 ve Temmuz 2019 tarihleri arasında Marmara Üniversitesi Tip Fakültesi Kulak Burun Boğaz ve Baş Boyun Cerrahisi Anabilim Dalı'nda ve Ümraniye Eğitim ver Araştırma Hastanesinde histoplatolojik olarak larenks yassı hücrelikarsinom(LYHK) tanısı ile opere edilmiş vakalar geriye dönük olarak taranmıştır. LYHK tanısı nedeni ile parsiyel larenjektomi operasyonu yapilan 47 adet vaka çalışmaya dahil edilmiştir. $\mathrm{Bu}$ araştırma Marmara Üniversitesi Etik Kurul tarafindan onaylanmış ve Helsinki Bildirgesi'ne uygun olarak yürütülmüştür.

Çalışmaya dahil edilen bütün hastaların medikal kayıtları incelenerek yaş, cinsiyet, sigara kullanımı, alkol kullanımı, operasyon bilgileri, preoperatif tedavi bilgileri, ek hastalık bilgileri, tümör evresi, tümör yerleşimi, tümör differansiyasyonu, cerrahi sinır pozitifliği,kıkırdak invazyonu, lenfovasküler invazyon, perinöral invazyon, lokorejyonel rekürrens gelişme durumu, postoperatif radyoterapi ve/veya kemoterapi gereksinimi ve ekstranodüler yayılım durumu (ENY) incelenerek dokümante edilmiştir.

\section{Istatiksel Analiz}

Çalışmada tanımlayıcı veriler kategorik verilerde $n, \%$ değerleri, sürekli verilerde ise ortalama, standart sapma, ortanca, minimummaksimum, çeyreksel (\%25-75 değerleri) değerlerden veriye uygun olanı ile gösterilmiştir. Sağkalım analizlerinin sunumunda ortalama ve $\% 95$ güven aralığ verileri kullanılmıştır. Kategorik verilerin karşılaştırılmasında Ki-Kare ve Fisher testleri kullanılmıştır. Normal dağılım göstermeyen ölçümsel verilerin karşılaştırılması için Kruskal Wallis testi kullanılmıştır. Tek değişkenli sağkalım analizlerinde karşılaştırmalar LogRank (Kaplan Meier) testi ile gerçekleştirilmiştir. Çok değişkenli sağkalım analizleri için Cox Regresyon Modellemesi kullanılmıştır. Tüm analizlerde istatistiksel anlamlılık için $\mathrm{p}<0,05$ kabul edilmiştir. Analizler IBM (C) SPSS program 20 sürümü (SPSS Inc., Chicago, IL, USA) ile gerçekleştirilmiştir. 


\section{Bulgular:}

Yapılan retrospektif değerlendirmede 43'ü erkek $(\% 91,5)$ ve 4'ü kadın $(\% 8,5)$ olmak üzere toplam $47 \mathrm{SKL}$ yapılan olgu çalışmaya dahil edilmiştir. Katılımcıların yaş ortalaması $61,9 \pm 7,9$ 'dur. Hastaların $\% 21,3$ 'ünde alkol,\%95.7'sinde sigara kullanımı mevcuttur. $\mathrm{Bu}$ hastaların başvurusu sırasında 29'unun erken evrede (\%61,7), 18 'inin ise ileri evrede $(\% 38,3)$ olduğu görülmüștür. Tümörün en s1k lokalize olduğu alan glottik bölgedir. Ortalama takip suresi ise $51.7 \pm 30,4$ aydır. (Tablo1)

Tablo 1. Hastaların sosyodemografik ve klinik özellikleri

\begin{tabular}{llrc}
\hline & & $\mathrm{n}$ & $\%$ \\
\hline \multirow{2}{*}{ Cinsiyet } & Erkek & 43 & 91,5 \\
& Kadın & 4 & 8,5 \\
\hline Alkol & Var & 10 & 21.3 \\
kullanımı & Yok & 37 & 78.7 \\
\hline Sigara & Var & 45 & 95.7 \\
kullanımı & Yok & 2 & 4.3 \\
\hline \multirow{3}{*}{ Lokalizasyon } & Supraglottis & 18 & 38.3 \\
& Glottis & 29 & 61.7 \\
\hline \multirow{4}{*}{$\begin{array}{l}\text { Histopatolojik } \\
\text { evre }\end{array}$} & İyi & 8 & 17 \\
& diferansiye & 31 & 66 \\
& Kötü & 8 & 17 \\
\hline \multirow{2}{*}{ Klinik evre } & diferansiye & & \\
\hline \multirow{2}{*}{$\begin{array}{l}\text { Erken evre } \\
\text { diseksiyonu }\end{array}$} & İleri evre & 18 & 38.3 \\
\hline & Yok & 25 & 53.2 \\
& İpsilateral & 11 & 23.4 \\
\hline & Bilateral & 11 & 23.4 \\
\hline
\end{tabular}

Hastaların tümör dokularındaki incelemede \%2,1'inde ekstra nodalyayilim (ENY), \%19,1'inde cerrahi sınır pozitif saptanmıştır. İncelemede tümörlerin \%10,6'sında k1kırdak invazyonu, \%27,7'sinde perinöral invazyon ve $\% 6,4$ 'ünde lenfovasküler invazyon saptanmıştır. Hastaların \%14,9'unda lokorejyonel rekürrens gelişmiştir. Takip süreci boyunca 10 hastada $(\% 21,3)$ herhangi bir sebebe bağl1 ölüm gerçekleşmiştir. (Tablo2)
Tablo 2. Hastaların klinik takip bulguları

\begin{tabular}{|c|c|c|c|}
\hline & & $\mathrm{n}$ & $\%$ \\
\hline \multirow{2}{*}{$\begin{array}{l}\text { Adjuvan } \\
\text { Radyoterapi }\end{array}$} & Var & 11 & 23.4 \\
\hline & Yok & 36 & 76.6 \\
\hline \multirow{2}{*}{$\begin{array}{l}\text { Adjuvan } \\
\text { Kemoterapi }\end{array}$} & Var & 4 & 8.5 \\
\hline & Yok & 43 & 91.5 \\
\hline \multirow{2}{*}{ Cerrahi sınır } & Pozitif & 9 & 19.1 \\
\hline & Negatif & 38 & 80.9 \\
\hline \multirow{2}{*}{$\begin{array}{l}\text { Kıkırdak } \\
\text { invazyonu }\end{array}$} & Var & 5 & 10.6 \\
\hline & Yok & 42 & 89.4 \\
\hline \multirow{2}{*}{$\begin{array}{l}\text { Perinöral } \\
\text { invazyon }\end{array}$} & Var & 13 & 27.7 \\
\hline & Yok & 34 & 72.3 \\
\hline \multirow{2}{*}{$\begin{array}{l}\text { Lenfovasküler } \\
\text { invazyon }\end{array}$} & Var & 3 & 6.4 \\
\hline & Yok & 44 & 93.6 \\
\hline \multirow{2}{*}{$\begin{array}{l}\text { Lokorejyonel } \\
\text { nüks }\end{array}$} & Var & 7 & 14.9 \\
\hline & Yok & 40 & 85.1 \\
\hline \multirow{2}{*}{$\begin{array}{l}\text { Sağkalım } \\
\text { durumu }\end{array}$} & Ölüm & 10 & 21.3 \\
\hline & Sağ & 37 & 78.7 \\
\hline
\end{tabular}

Supraglottik yerleşimli tümörler, glottik yerleşimli tümörlere göre daha ileri $T$ evresinde oldukları görülmüş ve tümör yerleşimi ve $\mathrm{T}$ evre ilişkisi istatistiki olarak anlamlı saptanmıştır (p <0.001) (Tablo 3). Bununla birlikte klinik evre ile tümör differansiyasyonu, cerrahi sinır, kıkırdak invazyonu, lenfovasküler invazyon, perinöral invazyonu, lokorejyonel rekürrens arasında anlamlı ilişki saptanamamıştır.

Tablo 3. Tümör evresine göre lokalizasyon durumu

\begin{tabular}{llllll}
\hline & & Supraglottis & Glottis & Total & P değeri \\
\hline T & 1 & 1 & 23 & 24 & 0.000 \\
\cline { 2 - 5 } & 2 & 4 & 3 & 7 & \\
\cline { 2 - 5 } 3 & 12 & 3 & 15 & \\
\cline { 2 - 5 } 4 & 1 & & & & \\
\hline Total & 18 & & & & \\
\hline
\end{tabular}


Lenf nodu tutulumuyla klinik bulgular arasındaki ilişki değerlendirildiğinde, supraglottik yerleşimli tümörlerde glottik yerleşimli tümörlere göre lenf nodu tutulumu anlamlı derecede daha yüksek saptanmıştır ( $p$ $<0.019$ ) (Tablo 4). İleri evre tümörlerde de erken evre tümörlere göre lenf nodu tutulumu daha yüksek saptanmıştır $\quad(p=0.019)$. Histopatolojik olarak lenf nodu pozitif olan olgularda lokorejyonel nüks anlamlı derecede daha yüksek saptanmıştır ( $p=0.02$ ). Bununla birlikte lenf nodu tutulumu ile tümör differansiyasyonu, cerrahi sınır, kıkırdak invazyonu, lenfovasküler invazyon ve perinöral invazyonu arasında anlamlı ilişki saptanamamıştır.
Kaplan Meier sağkalım analizleri neticesinde 3 -y1llık ve 5-yıllık genel sağkalım $\% 85,2$ ve $\% 74,5$ olarak saptanmıştır. Cerrahi sinır pozitif olgularda 3 -yıllık ve 5-y1llık genel sağkalım \%87,5 ve \%72,9 iken cerrahi sınır negatif olgularda 3 -y1llik ve 5 -y1ll1k genel sağkalım \%84.5 ve $\% 75.2$ olarak saptanmıştır (Tablo 5). Erken evre olgularda 3-y1llik ve 5y1llık genel sağkalım \%88,5 ve \%77,4 iken ileri evre olgularda 3 -y1llı ve 5-y1llk genel sağkalım \%79,1 ve \%69,2 olarak saptanmıştır (Tablo 6).

Tablo 4. Lenf nodu tutulumunun lokalizasyonlara göre dağılımı

\begin{tabular}{llllll}
\hline & & Supraglottis & Glottis & Total & P değeri \\
\hline Lenfnodu & negative & 12 & 27 & 39 & 0.019 \\
& positive & 6 & & & \\
\hline Total & & 18 & 29 & 47 & \\
\hline
\end{tabular}

Tablo 5. Cerrahi sınır ve genel sağkalım ilişkisi

\begin{tabular}{lcll} 
Cerrahi sınır & 3- y1llik & 5- y1llı & Genel \\
\hline negatif & $\% 84.5$ & $\% 75.2$ & $78.9 \%$ \\
\hline pozitif & $\% 87.5$ & $\% 72.9$ & $77.8 \%$ \\
\hline
\end{tabular}

Tablo 6. Evre ve sağkalım ilişkisi

\begin{tabular}{llll}
\hline & 3 -y1llk & 5-y1ll1k & Genel \\
\cline { 2 - 4 } Erken evre & $\% 88.5$ & $\% 77.4$ & $79.3 \%$ \\
\cline { 2 - 4 } İleri evre & $\% 79.1$ & $\% 69.2$ & $77.8 \%$ \\
\hline
\end{tabular}




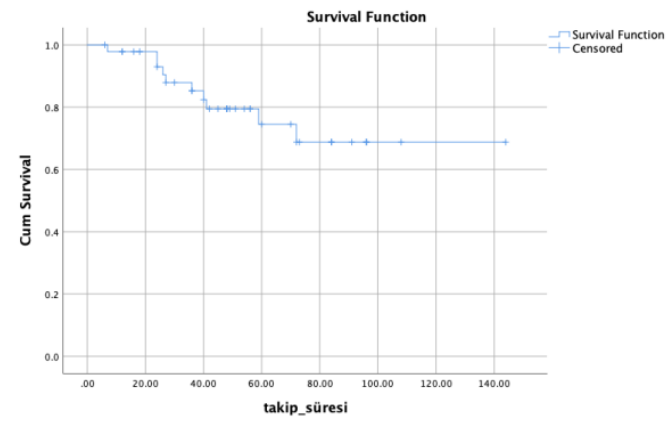

Şekil 1. Genel sağkalım grafiği

\section{Tartışma}

Larenks kanseri tedavisinde tedavi başarısının değerlendirilmesinde en önemli iki ölçüt sağ kalım süresi ve organ fonksiyonun devamlılı̆gıdır. SKL tanımlandığ 1959yılından beri bu iki tedavi hedefine ulaşmak için önemli araçlardan biri olmuşlardır (3). Çalışmamızda iki tersiyer klinikte tedavileri yapılmış larenks kanseri hastalarının onkolojik sonuçları literatürle karşılaştırılarak paylaşı1mıştır.

Larenks tümör cerrahisinde son 20 yılda trans-oral cerrahi teknikler ve radyoterapi alanında teknolojik gelişmelerin etkisi ile özellikle erken evre hastalarda açık parsiyel larenks cerrahisi yapılma sıklığı azalmıştır (8). Buna rağmen erken evre tümörlerde tek modalite kullanımını sağlayabilmek, ileri evre tümörlerde de total larenjektomi gibi radikal cerrahilerden kaçınabilmek adına hala larenks kanseri pratiğinde önemini korumaktadır.

SKL glottik ve supraglottik larenks kanseri tedavisinde yaygın olarak kullanılantedavi seneklerinden biridir. LiteratürdeSKL'nin iyi fonksiyonel ve onkolojik sonuçlarını paylasan pek çokçalışma mevcuttur $(5,6,9-12)$. Uygun hasta seçimi iyi cerrahi sonuç için en önemli etkenlerden biri olarak karşımızaçıkmaktadır. $\mathrm{Bu}$ seçim sırasındahastanın fonksiyonel kapasitesi, lezyonun detaylı değerlendirilmesi yol göstericidir. İleri solunum disfonksiyonu, krikoaritenoid eklem tutulumu, önde $>10$ mm,arkada is $>5 \mathrm{~mm}$ infraglottik uzanım ve paraglottik ve preepiglottik alan invazyonu krikoidkartilaj ve ekstralarengeal invazyon önemli kontraendikasyonlardır.

Glottik tümörlerde bu sayılan kontraendikasyonlar nedeniyle erken evrelerde bile cerrahi kontraendikasyon oluşabilmektedir.Bizim serimizde de hastaların tanı aldıklarında \%61,7'sinin glottik tümörler olduğu izlenmektedir. Klinik evre açısından da bu tümörlerin çoğunluğunun ise erken evre tümörler olduğu görülmektedir. Buna neden olabilecek başka bir etkenin iseyutarken takı1ma hissi, yutma güçlüğü, kulak ağrısı gibi müphem şikayetlere neden olan supraglottik tümörlere kıyasla glottik tümörler erken evrelerde bile ses kısıklığı şikayetine neden olarak daha erken tanı konulma şansına sahiptirler (13).

Larenksin en küçük fonksiyonel birimi hareketli bir krikoraritenoid eklemdir ve suprakrikoid larenjektomi tekniği bu birimin korunmasina dayamamaktadır. SKL bu fonksiyonel larenks dokusunu geride bırakabilme şansını verse de onkolojik başarı açısından tümörün sağlam sınırlarla eksizyonu önemlidir ve bunu sağlamak larenks gibi anatomisi girift ve boyut olarak küçük bir organda her zaman mümkün olmayabilir. Hastalarımızın yaklaşık \%20'sinde cerrahi sınır pozitif izlenmiştir. Her ne kadar çalışmamızda cerrahi sınır pozitifliği ile sağ kalım ve lokorejyonel nüks arasında anlamlı bir ilişki saptanamamış olsa da cerrahi sınır pozitifliği hastalık prognozunda ve takibinde göz önünde bulundurulmalıdır.

Larenks kanserlerinde boyun metastazı bulunma oranlaritümörün anatomik yerleşimine göre değişiklik göstermektedir. Embriyolojik ve klinik çalışmalar göstermektedir ki supraglottik tümörlerde klinik N0 hastalarda bile çifttaraflı boyun metastazları saptanabilmekte ve bu metastazlar hastalıktekrarı ve tedavi başarısızlığının en önemli nedenlerinden biri haline gelmektedir. Bizim hasta grubumuzda da supraglottik bölge tümörlerinin $\% 30$ 'dan fazlasında pozitif lenf nodu operasyon sonrasi patolojik değerlendirmede saptanmış ve bu durumun glottik bölge tümörlerine göreanlamlı olarak yüksek olduğu gösterilmiştir.Bizim çalışmamızdaki bu hastalara da ameliyatta çıkarılan materyallerin histopatolojik incelemesi sonucunda cerrahi sinır pozitifliği,kartilaj tutulumu, boyunda metastatik lenf nodu tutulumu olması, ekstrakapsüllertutulum ve perinöral invazyon gibi faktörler dikkate alınarak multidisipliner olarak radyoterapi kararı verilmiştir.

SKL sonrasinda radyoterapi her ne kadar fonksiyonel sonuçları olumsuz etkileyeceği nedeniyle istenen bir durum olmasa da boyun hastalığ1 olan olgularda ve cerrahi sinir 
pozitifliği olan seçilmiş olgularda cerrahi tedaviye ek olarak uygulanabilir (14). Bizim klinik serimizde ise 11 hasta postoperatifadjuvan radyoterapi tedavisi almıştır. Radyoterapinin primer tedavi olarak kullanıldığı olgularda rezidütümörvarlığında veya rekürrens halinde sekonder tedavi olarak da SKL uygulanmaktadır. Bizim serimizde bu özellikte hastalar hiç olmasa da bu hastaları içeren klinik sonuçları son yıllarda artmaktadır (15). Radyoterapi sonrasisalvaj cerrahi olarak SKL yapılan olgularla primer SKL yapılan olgular karşılaştırıldığında lokal komplikasyon oranlarındaartış izlenirken genel komplikasyon oranlarında anlamlı fark saptanmamıştır (16, 17).

Literatürde sağkalım ve loko-rejyonel
kontrol oranları farklıçalışmalarca paylaşılmıştır. $\mathrm{Bu}$ oranlar seriler arasında farklılık göstermektedir. Beş yıllık genel sağkalım oranı \%67-\%95 ve lokal kontrol oranları \%88- \%95 olarakbildirilmiştir $(18,19)$. Ortalama 42 ay süreyle takip edilen bizim serimizde iseliteratürle uyumlu olarak 5 yıllık genel sağkalım oranı \%84,5 iken hastalıksız sağkalım oranı \%75,2 bulunmuştur.Sonuçlardaki bu farkl11ıkların uygun hasta seçimi ve sunulan hasta gruplarının karşılaştırılabilir dağılımlarda olmama yatmaktadır. $\mathrm{Bu}$ nedenlerle de hastaların tedavi planlarındatüm bireysel faktörlerin multidisipliner bir ekiple beraber değerlendirilmesi büyük önem arz etmektedir.

\section{Sonuç:}

Larenks kanserlerinin tedavisinde SKL önemli araçlardan biridir. Cerrahi teknik ve onkolojik kurallara bağlı kalındığında uygun hastalarda fonksiyonel bir larenksi koruyarak hastalarda kalıcı iyileşme sağlamak mümkündür. Hastaların ve hastalıkların bireysel farklılıkları dikkate alınarak doğru tedavi planı multidisipliner olarak yapılmalıdır.

\section{Kaynakça}

1. Nocini R, Molteni G, Mattiuzzi C, Lippi G. Updates on larynx cancer epidemiology. Chin J Cancer Res. 2020;32(1):18-25. doi:10.21147/j.issn.10009604.2020.01.03

2. Ferlito A, Silver CE, Howard DJ, Laccourreye O, Rinaldo A, Owen R. The role of partial laryngeal resection in current management of laryngeal cancer: A collective review. Acta Otolaryngol. 2000;120(4):456-465. doi:10.1080/000164800750045938

3. Majer E, Rieder W. Technique of laryngectomy permitting the conservation of respiratory permeability (cricohyoidopexy). Ann Otolaryngol Chir Cervicofac. 1959;76:677-683.

4. Piquet J, Desaulty A, Decroix G. Crico-hyoidoepiglotto- pexy: surgical technique and functional results. Ann Otolaryngol Chir Cervicofac. 1974;(91):681-686.

5. Laccourreye H, Laccourreye O, Weinstein G, Menard M, Brasnu D. Supracricoid laryngectomy with cricohyoidopexy: A partial laryngeal procedure for selected supraglottic and transglottic carcinomas. Laryngoscope. 1990;100(7):735-741. doi:10.1288/00005537-199007000-00009

6. Laccourreye H, Laccourreye O, Menard M, Weinstein G, Brasnu D. Supracricoid laryngectomy with cricohyoidoepiglottopexy: A partial laryngeal procedure for glottic carcinoma. Ann Otol Rhinol Laryngol. 1990;99(6):421-426. doi:10.1177/000348949009900601

7. Silver CE, Beitler JJ, Shaha AR, Rinaldo A, Ferlito A. Current trends in initial management of laryngeal cancer: The declining use of open surgery. Eur Arch Oto-Rhino-Laryngology. 2009;266(9):1333-1352. doi:10.1007/s00405-009-1028-2

8. Succo G, Crosetti E, Bertolin A, et al. Treatment for T3 to T4a laryngeal cancer by open partial horizontal laryngectomies: Prognostic impact of different pathologic tumor subcategories. Head Neck. 2018;40(9):1897-1908. doi:10.1002/hed.25176

9. Sewnaik A, Hakkesteegt MM, Meeuwis CA, De Gier HHW, Kerrebijn JDF. Supracricoid partial laryngectomy with cricohyoidoepiglottopexy for recurrent laryngeal cancer. Ann Otol Rhinol Laryngol. 2006;115(6):419-424. doi:10.1177/000348940611500604

10. Pinar E, Imre A, Calli C, Oncel S, Katilmis H. Supracricoid partial laryngectomy: Analyses of oncologic and functional outcomes. Otolaryngol Head Neck Surg (United States). 2012;147(6):10931098. doi:10.1177/0194599812457334

11. Wang PW, Abedini MR, Yang LX, et al. Gelsolin regulates cisplatin sensitivity in human head-andneck cancer. Int J Cancer. 2014;135(12):2760-2769. doi:10.1002/ijc.28928

12. Wang Y, Li X, Pan Z. Analyses of functional and oncologic outcomes following supracricoid partial laryngectomy. Eur Arch Oto-Rhino-Laryngology. 2015;272(11):3463-3468. doi:10.1007/s00405-0143363-1

13. Koroulakis A, Agarwal M. Cancer, Laryngeal. StatPearls Publishing; 2020. Accessed May 28, 2020. http://www.ncbi.nlm.nih.gov/pubmed/30252332

14. Laccourreye O, Hans S, Borzog-Grayeli A, Maulard-Durdux C, Brasnu D, Housset M. Complications of postoperative radiation therapy after partial laryngectomy in supraglottic cancer: A long-term evaluation. Otolaryngol Neck Surg. 2000;122(5):752-757. doi:10.1067/mhn.2000.98756

15. Yiotakis J, Stavroulaki P, Nikolopoulos T, et al. Partial laryngectomy after irradiation failure. Otolaryngol - Head Neck Surg. 2003;128(2):200209. doi:10.1067/mhn.2003.63

16. Ganly I, Patel S, Matsuo J. Analysis of postoperative complications of open partial 
laryngectomy. Head Neck. 2009;31(338):45.

17. Naudo P, Laccourreye $O$, Weinstein G, Jouffre V, Laccourreye H, Brasnu D. Complications and functional outcome after supracricoid partial laryngectomy with cricohyoidoepiglottopexy. Otolaryngol - Head Neck Surg. 1998;118(1):124129. doi:10.1016/S0194-5998(98)70388-2

18. Scola B, Fernández-Vega M, Martínez T, Fernández-Vega S, Ramirez C. Management of cancer of the supraglottis. Otolaryngol - Head Neck
Surg. 2001;124(2):195-198.

doi:10.1067/mhn.2001.112202

19. Bocca E. Sixteenth Daniel C. Baker, Jr, memorial lecture: Surgical management of supraglottic cancer and its lymph node metastases in a conservative perspective. Ann Otol Rhinol Laryngol. 1991;100(4):261-267. doi:10.1177/000348949110000401 